\title{
Regular Observation of De-Acclimatization and Randomized Controlled Research of Diagnostic Criteria of High Altitude De-Acclimatization Syndrome among Different Plateau Migrants Crowd after Their Return to the Plain
}

\section{Qiquan Zhou',2*, Shengyue Yang3, Zhencai Yuan4, Yinhu Wang5, Xuefeng Zhang6, Wei Gao', Zifu Shi', Youli Yang', Yunhong Wu'10, Yong Fan',2, Fuling Wang5, Guansong Wang11*}

\footnotetext{
${ }^{1}$ Department of High Altitude Disease, College of High Altitude Military Medicine, Third Military Medical University, Chongqing, China

${ }^{2}$ Key Laboratory of High Altitude Medicine of Ministry of Education and Key Laboratory of High Altitude Medicine of PLA, Chongqing, China

${ }^{3}$ Department of Respiratory Medicine, Fourth Hospital of Chinese PLA, Xining, China

${ }^{4}$ Xianyang Hospital of China Railway First Group Co., Ltd., Xianyang, China

${ }^{5}$ Research Institute of High Altitude Diseases, 18th Hospital of Chinese PLA, Yecheng, China

${ }^{6}$ Research Center of High Altitude Medicine, People's Hospital of Golmud City, Golmud, China

${ }^{7}$ Department of Thoracic Surgery, Lanzhou General Hospital of Lanzhou Command, Lanzhou, China

${ }^{8}$ The 68303 Troop Hospital of Chinese PLA, Wuwei, China

${ }^{9}$ Department of Clinical Laboratory, Tenth Hospital of Chinese PLA, Wuwei, China

${ }^{10}$ Department of Endocrinology, Hospital of Chengdu Office of Tibet Autonomous Region, Chengdu, China

${ }^{11}$ Research Institute of Respiratory Diseases, Xinqiao Hospital, Third Military Medical University, Chongqing, China

Email: *zhouqq9918@163.com,ysyday@163.com, yuanzhencai@163.com, xj18yywyh@sina.com, gemzxf@163.com, gaoweizy@126.com, szfszf111@163.com, youliyang58@163.com, wu yunhong@163.com, fangyongcq@163.com, wangfuling18@163.com, wanggs2003@163.com
}

Received 17 September 2014; revised 20 October 2014; accepted 10 November 2014

Copyright (C) 2014 by authors and Scientific Research Publishing Inc.

This work is licensed under the Creative Commons Attribution International License (CC BY).

http://creativecommons.org/licenses/by/4.0/

(c) (i) Open Access

\section{Abstract}

Objective: The objective of this study was to investigate the diagnostic methods of high altitude ${ }^{*}$ Corresponding authors.

How to cite this paper: Zhou, Q.Q., et al. (2014) Regular Observation of De-Acclimatization and Randomized Controlled Research of Diagnostic Criteria of High Altitude De-Acclimatization Syndrome among Different Plateau Migrants Crowd after Their Return to the Plain. Occupational Diseases and Environmental Medicine, 2, 86-100.

http://dx.doi.org/10.4236/odem.2014.24010 
de-acclimatization syndrome and to formulate diagnostic criteria. Methods: This study was conducted using epidemiological surveys and a multi-center randomized controlled clinical trial. A total of 3011 subjects were studied, and the following indices were collected after their return to low altitude areas from the plateau: general health status, blood, urine and stool samples, myocardial enzyme levels, liver and kidney function, nerve function, sex hormone levels, microalbuminuria, electrocardiogram (ECG), echocardiography, pulmonary function, and hemorheological markers. These data were compared to those of randomized healthy subjects in the same age range who lived at the same altitude to determine the characteristics of high altitude de-acclimatization syndrome. Based on these characteristics, diagnostic criteria for high altitude de-acclimatization syndrome were formulated. Results: This study demonstrated that the incidence of high altitude de-acclimatization syndrome was $84.36 \%$. Sixty percent of the cases were mild, $30 \%$ were medium, and $10 \%$ were severe. The incidence was higher among those who returned to a place of lower altitude, resided at a high altitude for a longer period of time, or engaged in heavy labor while at high altitude. Patients with high altitude de-acclimatization syndrome manifested hematological abnormalities and abnormal ventricular function, notably a right ventricular diastolic function, which recovered to baseline function after one to five years. Exposure to long-term hypoxia often caused obvious changes in cardiac morphology, i.e., left and right ventricular hypertrophy, particularly within the right ventricle. In addition, patients with high altitude de-acclimatization syndrome often presented with low blood pressure, low pulse pressure, and microalbuminuria. A few patients presented with occult blood in their feces. The diagnosis of high altitude de-acclimatization syndrome can be made if a patient who recently returns to the plain from the plateau complains of dizziness, weakness, sleepiness, chest tightness, edema, memory loss, and other symptoms and signs that do not alleviate under short-term rehabilitation or symptomatic treatment, and if organic diseases of the heart, lung, kidney, and other organs have been excluded. Conclusion: The diagnosis of high altitude de-acclimatization syndrome should be made after a comprehensive analysis of the patient's clinical symptoms and signs.

\section{Keywords}

Plateau Migrants, Low Altitude, High Altitude De-Acclimatization Syndrome, Diagnostic Criteria, Multi-Center Study

\section{Introduction}

High altitude de-acclimatization syndrome was called “drunk oxygen syndrome” in the past, and occurs when people, who normally live in plains, return to the plain after living in the plateau for a period of time. When they live in the plateau, a series of functional and structural changes would take place to make them adjust to acclimate the plateau. When they return to the plain, the body would readjust itself to acclimate the plain, so known as the high altitude de-acclimatization syndrome [1] [2]. High altitude de-acclimatization is one's adaptation to a normal-oxygen environment after leaving an oxygen-deficient plateau [3] [4]. When returning to a normal oxygen environment after living in the oxygen-deficient plateau, an individual loses the plateau adaption, thus leading to de-acclimatization or de-acclimatization [5]. In the past, there were much available information regarding the syndrome, and the causes of de-acclimatization were rarely studied; therefore, no standard diagnostic criteria or even effective prophylactic measures have been developed. To some extent, this lack of knowledge affected the physical and mental health, work efficiency, or even daily life of patients with de-acclimatization syndrome [6]-[8]. Therefore, we conducted this multi-center randomized controlled clinical trial of individuals who returned from the plateau to the plain to formulate diagnostic criteria and guide treatment.

\section{Subjects and Methods}

\subsection{Methods}

\subsubsection{Subjects}

The study subjects included 1320 officers and soldiers who returned from Yushu, Qinghai to their homes (Wu- 
wei, Gansu; Zepu, Xinjinag; Tongliang, Chongqing; Xianyang, Shaanxi; Chengdu, Sichuang; Xining, Qinghai; Zhengzhou, Henan; Hangzhou, Zhejiang, etc.). The study subjects included 115 officers and soldiers who returned to the plain after working in Hargoolun Range for at least one year, 940 officers and soldiers who returned to the plain after working in the plateau for at least three years, 300 railway workers who returned to the plain after constructing the second stage of Qinghai-Xizang Railway for at least five years, 500 cadres who returned to the plain after working in Xizang for at least 10 years, and 110 cadres who came to the plain for shorttime recuperation. The subjects were selected by the standard criteria. All subjects had recently returned to the plain from the plateau and did not have any heart, lung, brain, kidney, or other primary organ diseases. This study was approved by the medical ethical committee of the Third Military Medical University. All participants signed informed consent form.

\subsubsection{Methods}

This study was conducted as an epidemiological survey and prospective clinical trial. Specially assigned persons handed out self-designed health survey questionnaires on the second [9] [10], 16th, 30th, 90th, and 360th days after the subjects returned to the plain. The questionnaire mainly contained general information, the date on which the subject went to the plateau, the date of return to the plain, the altitude of the plateau, major symptoms and signs after returning to the plain (such as dizziness, fatigue, weakness, sleepiness, insomnia, dreaminess, cyanosis, chest tightness, palpitation, anorexia, constipation, diarrhea, abdominal distension, edema, memory loss, slow reaction, slow pulse, sexual dysfunction, weight loss, tooth loss, hair loss, precordial pain, numbness of hands and feet, hemorrhagic spots, and ecchymosis), and their severity and frequency. Some difficult medical terms were explained when the subjects were filling in the questionnaire. The questionnaires were filled in with facts and reclaimed as soon as they were completed. According to the inclusion and exclusion criteria for high altitude de-acclimatization syndrome, 3011 of the 3285 subjects were included in the study. The 3011 subjects were scored according to the grading and evaluation criteria for high altitude de-acclimatization syndrome. The prospective clinical trial consisted of physical examination at local clinics. The examination included 22 items such as routine blood tests, urine and stool tests, microalbuminuria, myocardial enzymes, liver and kidney function, nerve function, electrocardiogram (ECG), echocardiography, sex hormones, cytokines, oxygen free radicals, and neuron specific enolase.

\subsubsection{Statistical Analysis}

The data were analyzed using SPSS 17.0. The measurement data were recorded as $x \pm s$. The comparison between groups was first made using homogeneity of variance. Then, a one-way analysis of variance was used if the variance was homogenous; otherwise, Tamhane was used. Cluster and partial correlation analyses were used to compare the incidence. The differences were considered statistically significant at $P<0.05$.

\section{Results}

\subsection{High Altitude De-Acclimatization Syndrome Symptoms and Their Frequency}

Of the 3011 subjects, 2540 (84.36\%) presented with de-acclimatization symptoms (Table 1). The most frequent symptoms were dizziness, fatigue, chest tightness, weakness, sleepiness, insomnia, anemia, vertigo, poor concentration, memory loss, cough, dreaminess, weight loss, slow reaction time, numbness of hands and feet, and increased appetite. The incidences of fatigue, weakness, and sleepiness were $69.4 \%, 65.6 \%$, and $63.4 \%$, respectively (Table 2). These three symptoms affected the subjects' daily life and ability to work. The incidence of high altitude de-acclimatization syndrome in some groups of subjects was 99\% (Table 1).

\subsection{Severity of High Altitude De-Acclimatization Symptoms}

All subjects with high altitude de-acclimatization symptoms were classified. The severity of 11 other frequently occurring symptoms was analyzed (Figure 1). It was found that $60 \%$ of the symptoms were mild, $30 \%$ were moderate, and $10 \%$ were severe. Most subjects with high altitude de-acclimatization syndrome recovered without any treatment, while a few recovered after proper treatment. The disease affected the daily life and work of the subjects studied. 
Table 1. Incidence of high altitude de-acclimatization in different populations.

\begin{tabular}{ccccc}
\hline Population & $\begin{array}{c}\text { Number of } \\
\text { subjects (n) }\end{array}$ & $\begin{array}{c}\text { Altitude of the } \\
\text { resided in (m) }\end{array}$ & $\begin{array}{c}\text { Subjects with } \\
\text { de-acclimatization } \\
\text { (cases) }\end{array}$ & $\begin{array}{c}\text { Incidence of } \\
\text { de-acclimatization } \\
\text { (\%) }\end{array}$ \\
\hline A motorized infantry brigade in Wuwei, Gansu & 1014 & 1350 & 1004 & 99.00 \\
An armed police unit in Chongqing & 744 & 300 & 583 & 78.36 \\
A fire corps in Chongqing & 152 & 300 & 107 & 70.39 \\
A cadres retreat in Chengdu & 362 & 500 & 317 & 87.65 \\
A cadres retreat in Zhengzhou & 102 & 110 & 84 & 82.35 \\
A border defense group in Zepu, Xinjiang & 113 & 1215 & 75 & 84.07 \\
An air force unit in Chongqing & 123 & 300 & 139 & 60.97 \\
A fire corps in Sichuan & 210 & 500 & 72 & 66.19 \\
A cadres retreat in Beijing & 86 & 30 & 64 & 83.72 \\
A cadres retreat in Kunming & 105 & 1890 & & 60.95 \\
\hline
\end{tabular}

Table 2. Incidence of high altitude de-acclimatization in 1014 soldiers.

\begin{tabular}{|c|c|c|c|c|c|}
\hline Symptoms & $\begin{array}{l}\text { Number of subjects with } \\
\text { symptoms (cases) }\end{array}$ & $\begin{array}{l}\text { Incidence } \\
\text { (\%) }\end{array}$ & Symptoms & $\begin{array}{l}\text { Number of subjects with } \\
\text { symptoms (cases) }\end{array}$ & $\begin{array}{c}\text { Incidence } \\
(\%)\end{array}$ \\
\hline Dizziness & 496 & 48.9 & $\begin{array}{l}\text { Unable to } \\
\text { concentrate }\end{array}$ & 487 & 48.0 \\
\hline Tiredness & 704 & 69.4 & Memory loss & 416 & 41.0 \\
\hline Fatigue & 665 & 65.6 & Weight loss & 393 & 38.8 \\
\hline Sleepiness & 643 & 63.4 & Unresponsive & 301 & 29.7 \\
\hline Cyanosis & 153 & 15.1 & Numbness & 211 & 20.8 \\
\hline Chest tightness & 311 & 30.7 & Increased appetite & 206 & 20.3 \\
\hline Palpitation & 299 & 29.5 & Precordial pain & 168 & 16.6 \\
\hline Anorexia & 175 & 17.3 & Slow pulse & 109 & 10.8 \\
\hline Constipation & 158 & 15.6 & $\begin{array}{l}\text { Lower extremity } \\
\text { edema }\end{array}$ & 94 & 9.3 \\
\hline Diarrhea & 80 & 7.9 & Sexual dysfunction & 94 & 9.3 \\
\hline Abdominal pain & 187 & 18.4 & Hair loss & 88 & 8.7 \\
\hline Abdominal distension & 148 & 14.6 & Nocturia & 92 & 9.1 \\
\hline Cough & 246 & 24.3 & $\begin{array}{l}\text { Unstable blood } \\
\text { pressure }\end{array}$ & 92 & 9.1 \\
\hline Sputum & 250 & 24.7 & Skin bleeding & 81 & 8.0 \\
\hline Asthma & 93 & 9.2 & Skin ecchymosis & 81 & 8.0 \\
\hline Sore throat & 215 & 21.2 & Weight gain & 114 & 11.2 \\
\hline Light-headedness & 392 & 38.7 & Facial swelling & 70 & 6.9 \\
\hline
\end{tabular}

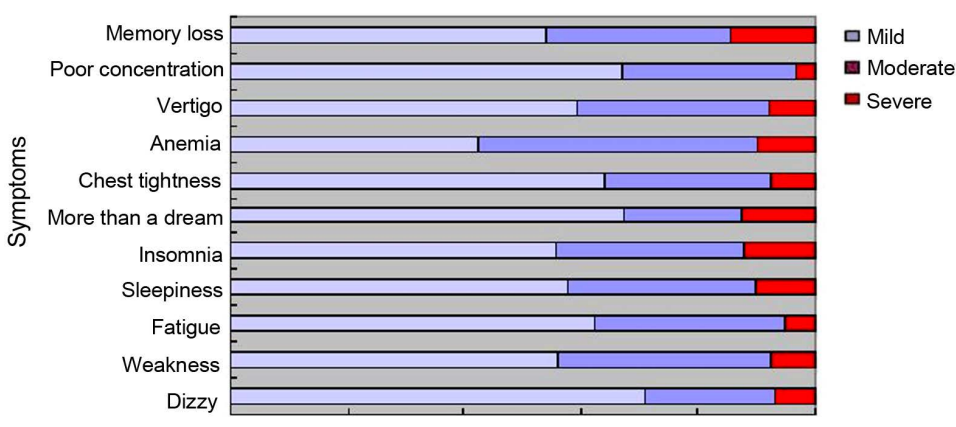

Figure 1. Severity of 11 additional frequently occurring high-altitude deacclimatization symptoms. 


\subsection{Altitude of the Return Location and High Altitude De-Acclimatization Syndrome}

High altitude de-acclimatization syndrome was related to the altitude of the plain to which the subjects returned. Subjects with a return location at lower altitudes exhibited higher incidence rates of high altitude de-acclimantization syndrome. For example, the incidences of high altitude de-acclimatization syndrome among the subjects who returned to Kunming (1891 m), Zhengzhou (111 m), and Beijing (31 m) were 60.95\%, 82.35\%, and $83.72 \%$, respectively. The incidence in the subjects who returned to Beijing or Zhengzhou was significantly higher than that of Kunming (Table 3).

The incidences of high altitude de-acclimatization syndrome among the subjects who returned to Kunming, Zhengzhou, and Beijing after living in high altitude for 10 years were $47.50 \%, 66.67 \%$, and $67.65 \%$, respectively. The incidences of those who returned to Kunming, Zhengzhou, and Beijing after living in high altitude for more than 20 years were $69.63 \%, 93.33 \%$, and 94.23\%, respectively. The differences between the two groups were statistically significant (Table 4). The result demonstrated that the study subjects were more likely to suffer from de-acclimatization when returning to low altitude after living in high altitude for a longer period of time.

The incidences of high altitude de-acclimatization syndrome among the subjects who returned to Kunming, Zhengzhou, and Beijing from Xizang were 68.75\%, 89.66\%, and 92\%, respectively. The incidences of those who returned to Kunming, Zhengzhou, and Beijing from Golmud, Qinghai were 48.78\%, 72.22\%, and 72.73\%, respectively. The differences between the two groups were statistically significant (Table 5). The result indicated that the subjects were more likely to experience de-acclimatization syndrome if the returned from a higher plateau.

Table 3. Incidence of high altitude de-acclimatization in plateau migrants after their return to three low-altitude areas.

\begin{tabular}{ccccc}
\hline Areas (altitude) & Subjects & With symptoms & Without symptoms (cases) & Incidence (\%) \\
\hline Kunming $(1891 \mathrm{~m})$ & 105 & 64 & 41 & 60.95 \\
Zhengzhou $(111 \mathrm{~m})$ & 102 & 84 & 18 & 82.35 \\
Beijing $(31 \mathrm{~m})$ & 86 & 72 & 14 & 83.72 \\
Total & 293 & 220 & 83 & 75.09 \\
\hline
\end{tabular}

Table 4. Incidences of high altitude de-acclimatization in people who returned to three different low-altitude areas after living in the plateau for different periods of time.

\begin{tabular}{ccccccc} 
& \multicolumn{3}{c}{ Lived in high altitude for 10 years } & \multicolumn{3}{c}{ Lived in high altitude for more than 20 years } \\
\cline { 2 - 7 } Areas & Subjects & With symptoms (cases) & Incidence (\%) & Subjects & With symptoms (cases) & Incidence (\%) \\
\hline Kunming & 40 & 19 & 47.50 & 65 & 45 & 69.23 \\
Zhengzhou & 42 & 28 & 66.67 & 60 & 56 & 93.33 \\
Beijing & 34 & 23 & 67.65 & 52 & 49 & 94.23 \\
\hline
\end{tabular}

Table 5. Incidences of high altitude de-acclimatization in subjects who returned to three different low-altitude areas after living in plateaus of different altitudes.

\begin{tabular}{ccccccc}
\hline \multirow{2}{*}{ Areas } & \multicolumn{3}{c}{ Lhasa areas (3650 m) } & \multicolumn{2}{c}{ Golmud areas (2780 m) } \\
\cline { 2 - 7 } & Subjects & With symptoms (cases) & Incidence (\%) & Subjects & With symptoms (cases) & Incidence (\%) \\
\hline Kunming & 64 & 44 & 68.75 & 41 & 20 & 48.78 \\
Zhengzhou & 58 & 52 & 89.66 & 44 & 32 & 72.73 \\
Beijing & 50 & 46 & 92.00 & 36 & 26 & 72.22 \\
\hline
\end{tabular}




\subsection{Effects of Labor Intensity in the Plateau on Recovery from High Altitude De-Acclimatization Syndrome in the Plain}

After returning to the plain, the subjects who performed heavy physical labor in the plateau were more likely to develop high altitude de-acclimatization syndrome than were those who did not. These subjects also required a longer recovery time (Table 6). In addition to the altitude-related symptoms, such as dizziness, fatigue, weakness, and sleepiness, the subjects experienced other symptoms related to labor intensity, i.e., more intense labor led to more severe symptoms. The differences in the severity of the symptoms between those who did heavy labor and those who did light labor were statistically significant $(P<0.05)$. This result revealed that labor intensity on the plateau was correlated with high altitude de-acclimatization syndrome on the plain.

\subsection{The Effects of Mountain Sickness on Ventricular Function and Pulmonary Arterial Pressure after Return to the Plain}

The severity of mountain sickness among people who returned to the plateau from the plain was directly related to the severity of high altitude de-acclimatization syndrome after return to the plain. The subjects who had more severe mountain sickness in the plateau presented with more frequent and severe symptoms of high altitude deacclimatization in the plain. In addition, these subjects recovered more slowly. Moreover, these subjects had higher pulmonary arterial pressure and lower cardiac function. The subjects who returned to the plateau from the plain rapidly and performed heavy labor for 50 days presented with obvious right ventricular hypertrophy and decreased left ventricular function that aggravated the deterioration of mountain sickness (Table 7 and Table 8 ).

Table 6. Effects of different altitudes and labor intensity on the incidence of high altitude de-acclimatization after return to low altitude areas.

\begin{tabular}{|c|c|c|c|c|}
\hline \multirow{2}{*}{ Symptoms } & \multicolumn{2}{|c|}{ Strong physical labor group at $3700 \mathrm{~m}$ (243 persons) } & \multicolumn{2}{|c|}{ Light physical labor group at $4200 \mathrm{~m}$ (300 persons) } \\
\hline & With symptoms (cases) & Incidence (\%) & With symptoms (cases) & Incidence (\%) \\
\hline Dizziness & 150 & 61.7 & 193 & 64.3 \\
\hline Tiredness & 194 & 79.8 & 250 & 83.3 \\
\hline Fatigue & 184 & 75.7 & 234 & 78.0 \\
\hline Sleepiness & 174 & 71.6 & 254 & $81.7^{(1)}$ \\
\hline Cyanosis & 89 & 36.6 & 57 & $19.0^{(1)}$ \\
\hline Chest tightness & 122 & 50.2 & 117 & $39.0^{(1)}$ \\
\hline Constipation & 77 & 31.7 & 54 & $18.0^{(1)}$ \\
\hline Diarrhea & 84 & 34.6 & 79 & $26.3^{(1)}$ \\
\hline Abdominal pain & 95 & 39.1 & 66 & $22.0^{(1)}$ \\
\hline Abdominal distension & 65 & 26.8 & 129 & $43.0^{(1)}$ \\
\hline Cough & 101 & 41.6 & 85 & $28.3^{(1)}$ \\
\hline Sputum & 105 & 43.2 & 95 & $31.7^{(1)}$ \\
\hline Light-headedness & 130 & 53.5 & 128 & $42.7^{(1)}$ \\
\hline $\begin{array}{l}\text { Lower extremity } \\
\text { edema }\end{array}$ & 58 & 23.9 & 29 & $9.7^{(1)}$ \\
\hline Unresponsive & 112 & 46.1 & 105 & $35.0^{(1)}$ \\
\hline Slow pulse & 54 & 22.2 & 29 & $9.7^{(1)}$ \\
\hline Numbness & 84 & 34.6 & 72 & $24.0^{(1)}$ \\
\hline Facial swelling & 140 & 57.6 & 26 & $8.7^{(1)}$ \\
\hline $\begin{array}{l}\text { Unstable blood } \\
\text { pressure }\end{array}$ & 50 & 20.6 & 32 & $10.7^{(1)}$ \\
\hline Precordial pain & 74 & 30.5 & 62 & $20.7^{(1)}$ \\
\hline
\end{tabular}

${ }^{(1)} \mathrm{P}<0.05$ compared with strong physical labor group at $3700 \mathrm{~m}$. 
Table 7. Relationship between the severity of mountain sickness and left ventricular function after return to low altitude from high altitude $(\bar{x} \pm s)$.

\begin{tabular}{|c|c|c|c|c|c|}
\hline Group & Cases & RVID/LVID (\%) & Tei index & LVEF (\%) & LVFS (\%) \\
\hline SAMS group & 24 & $51.97 \pm 3.22$ & $0.59 \pm 0.07$ & $41.42 \pm 3.97$ & $23.24 \pm 2.61$ \\
\hline MAMS group & 47 & $46.33 \pm 3.37^{(1)}$ & $0.49 \pm 0.05^{(1)}$ & $47.64 \pm 5.05^{(1)}$ & $26.72 \pm 1.78^{(1)}$ \\
\hline NAMS group & 25 & $39.28 \pm 3.26^{(1)}$ & $0.38 \pm 0.05^{(2)}$ & $58.22 \pm 4.34^{(2)}$ & $32.15 \pm 2.32^{(2)}$ \\
\hline PC group & 50 & $35.94 \pm 2.86^{(1)(2)}$ & $0.31 \pm 0.03^{(1)(2)(3)}$ & $64.73 \pm 4.38^{(1)(2)(3)}$ & $36.76 \pm 2.37^{(1)(2)(3)}$ \\
\hline
\end{tabular}

${ }^{(1)} P<0.01$ compared with SAMS group; ${ }^{(2)} P<0.01$ compared with MAMS group; ${ }^{(3)} P<0.01$ compared with NAMS group; SMS: Severe mountain sickness; MAMS: Mild mountain sickness; NAMS: No mountain sickness; PC: Plain control; RVID/LVID: Right ventricular internal diameter/Left ventricular internal dimension; Tei index. Myocardial performance index; LVEF: Left ventricular ejection fraction; LVFS: Left ventricular tractional shortening.

Table 8. Relationship between the severity of mountain sickness and right ventricular function after return to low altitude from high altitude $(\bar{x} \pm s)$.

\begin{tabular}{cccccc}
\hline Group & Cases & mPAP $(\mathrm{mmHg})$ & RVID (mm) & RVOT (mm) & $35.87 \pm 4.26$ \\
SAMS group & 24 & $34.70 \pm 2.94$ & $24.64 \pm 3.15$ & $32.46 \pm 4.12$ & $46.75 \pm 3.81$ \\
MAMS group & 47 & $28.42 \pm 1.32^{(1)}$ & $21.57 \pm 2.78$ & $29.89 \pm 3.77^{(1)}$ & $47.68 \pm 3.65$ \\
NAMS group & 25 & $24.23 \pm 1.56^{(1)}$ & $18.91 \pm 2.45^{(1)}$ & $16.76 \pm 2.07^{(1)(2)}$ & $27.33 \pm 3.66^{(1)(2)(3)}$ \\
PC group & 50 & $18.50 \pm 1.30^{(1)(2)(3)}$ & $46.52 \pm 3.49$ \\
\hline
\end{tabular}

${ }^{(1)} P<0.01$ compared with SAMS group; ${ }^{(2)} P<0.01$ compared with MAMS group; ${ }^{(3)} P<0.01$ compared with NAMS group; SMS: Severe mountain sickness; MAMS: Mild mountain sickness; PC: Plain control; mPAP: Mean pulmonary arterial pressure; RVID: Right ventricular internal diameter; RVOT: Right ventricular outflow tract; LVID: Left ventricular internal dimension.

\subsection{Recovery Time of Left and Right Ventricular Functions after Return to Low Altitude}

The same group of people was observed at different times. After exposure to high altitude for 50 days, the mPAP, RVID, RVOT, Tei indices, and RVID/LVID increased significantly, whereas LVEF decreased significantly. Twelve hours after the return to low altitude, the mPAP, RVID, RVOT, Tei indices, and RVID/LVID decreased significantly, whereas LVEF increased significantly. Fifteen days after the return to low altitude, the mPAP, LVID, LVEF and Tei indices returned to normal in the plain controls, whereas RVID, RVOT, and RVID/LVID did not return to normal until 30 days after return to low altitude (Table 9 and Table 10).

\subsection{Changes in Cardiothoracic Ratios}

Based on the altitude of their residence, 517 subjects who had lived in the plateau for more than three years were classified. X-ray examination showed that their cardiothoracic ratios were significantly higher than those of the plain controls $(P<0.01$, Table 11). Forty months after they returned to the plain, their cardiothoracic ratios were still significantly higher than those of the plain controls $(P<0.05$, Table 12). These results suggested that the cardiothoracic ratio would not return to normal after a short time on the plain.

\subsection{Changes in the Hematological Indices among Plateau Migrants after Return to the Plain}

\subsubsection{Changes in the Hematological Indices among People Who Returned to the Plain after Short-Term Exposure to the Plateau}

The hematological indices among people who returned to the plain after short-term exposure to the plateau were observed. It was found that 30 days after return to the plain, the white blood cell (WBC) count, red blood cell (RBC) count, hemoglobin (Hb), hematocrit (Hct), mean corpuscular volume (MCV), and mean corpuscular hemoglobin $(\mathrm{MCH})$ were all significantly higher than those of the plain controls $(P<0.05)$, but the platelet (Plt) count was much lower than that of the plain controls $(P<0.05$, Table 13). Over time, these test parameters tended to return to normal. 
Table 9. Metergasis of the right ventricles of plateau migrants after they returned to low altitude at different times ( $\bar{x} \pm s$ ).

\begin{tabular}{cccccc}
\hline Time points & Cases & mPAP $(\mathrm{mmHg})$ & RVID $(\mathrm{mm})$ & RVOT (mm) & RVID/LVID (\%) \\
\hline 50 d exposure to high altitude & 96 & $29.08 \pm 4.22$ & $21.63 \pm 2.79$ & $32.73 \pm 4.05$ & $45.86 \pm 3.53$ \\
12 h after return to low altitude & 96 & $23.05 \pm 3.18^{(1)}$ & $19.75 \pm 2.48^{(1)}$ & $30.96 \pm 3.52$ & $42.16 \pm 3.34$ \\
15 d after return to low altitude & 96 & $18.96 \pm 1.75^{(2)}$ & $18.01 \pm 2.23^{(1)}$ & $29.29 \pm 3.22$ & $38.22 \pm 2.96$ \\
30 d after return to low altitude & 96 & $18.63 \pm 1.22^{(1)(2)(3)}$ & $16.82 \pm 1.87^{(1)(2)}$ & $27.47 \pm 3.34^{(1)(2)}$ & $35.43 \pm 2.77^{(1)(2)}$ \\
Plain control & 50 & $18.50 \pm 1.30^{(1)(2)}$ & $16.76 \pm 2.07^{(1)(2)}$ & $27.33 \pm 3.66^{(1)}$ & $35.94 \pm 2.86^{(1)(2)}$ \\
\hline
\end{tabular}

${ }^{(1)} \mathrm{P}<0.01$ compared with $50 \mathrm{~d}$ exposure to high altitude; ${ }^{(2)} \mathrm{P}<0.01$ compared with $12 \mathrm{~h}$ after return to low altitude; ${ }^{(3)} \mathrm{P}<0.01$ compared with $15 \mathrm{~d}$ after return to low altitude; mPAP: Mean pulmonary arterial pressure; RVID: Right ventricular internal diameter; RVOT: Right ventricular outflow tract; LVID: Left ventricular internal dimension.

Table 10. Metergasis of left ventricles of plateau migrants after return to low altitude at different times $(\bar{x} \pm s)$.

\begin{tabular}{ccccc}
\hline Time points & Cases & LVID $(\mathrm{mm})$ & LVEF $(\%)$ & Tei index \\
\hline 50 d exposure to high altitude & 96 & $47.21 \pm 3.58$ & $48.71 \pm 6.81$ & $0.49 \pm 0.05$ \\
$12 \mathrm{~h}$ after return to low altitude & 96 & $46.82 \pm 3.37$ & $55.87 \pm 6.07^{(1)(2)}$ & $0.39 \pm 0.05^{(1)}$ \\
15 d after return to low altitude & 96 & $47.12 \pm 3.46$ & $63.50 \pm 4.45^{(1)(2)}$ & $0.31 \pm 0.04^{(1)(2)}$ \\
30 d after return to low altitude & 96 & $46.78 \pm 3.24$ & $63.96 \pm 4.11^{(1)(2)}$ & $0.30 \pm 0.03^{(1)(2)}$ \\
Plain control & 50 & $46.52 \pm 3.49$ & $64.73 \pm 4.38^{(1)}$ & $0.31 \pm 0.03^{(1)(2)}$ \\
\hline
\end{tabular}

${ }^{(1)} \mathrm{P}<0.01$ compared with 50 d exposure to high altitude; ${ }^{(2)} \mathrm{P}<0.01$ compared with $12 \mathrm{~h}$ after return to low altitude; LVID: Left ventricular internal dimension; LVEF: Left ventricular ejection fraction; Tei index. Myocardial performance index.

Table 11. Cardiothoracic ratio of subjects residing at different altitudes $(\bar{x} \pm s)$.

\begin{tabular}{ccc}
\hline Altitude $(\mathrm{m})$ & People of investigation (cases) & Cardiothoracic ratio (\%) \\
\hline Plain control & 220 & $0.494 \pm 0.018$ \\
$3000-3750$ & 200 & $0.498 \pm 0.023^{(1)}$ \\
$3751-4500$ & 120 & $0.499 \pm 0.024^{(1)}$ \\
$>4500$ & 197 & $0.504 \pm 0.023^{(1)}$ \\
\hline
\end{tabular}

${ }^{(1)} P<0.05$ compared with plain control.

Table 12. Cardiothoracic ratio of subjects residing in plateau after return to the plain at different times ( $\bar{x} \pm s)$.

\begin{tabular}{ccc}
\hline Time (months) & People of investigation (cases) & Cardiothoracic ratio (\%) \\
\hline Plain control & 220 & $0.494 \pm 0.018$ \\
$0-20$ & 82 & $0.496 \pm 0.022$ \\
$21-40$ & 358 & $0.498 \pm 0.023^{(1)}$ \\
$>40$ & 77 & $0.499 \pm 0.024^{(1)}$ \\
\hline
\end{tabular}

${ }^{(1)} P<0.05$ compared to the plain controls.

Table 13. Select hematological indices of rescue personnel after return to low altitude ( $\bar{x} \pm s)$.

\begin{tabular}{ccccccc}
\hline Group & Cases & WBC $\left(\times 10^{9} / \mathrm{L}\right)$ & RBC $\left(\times 10^{12} / \mathrm{L}\right)$ & Hb $(\mathrm{g} / \mathrm{L})$ & Hct $(\%)$ & Plt $\left(\times 10^{9} / \mathrm{L}\right)$ \\
\hline $\begin{array}{c}\text { Plain control group } \\
\begin{array}{c}15 \mathrm{~d} \text { after return } \\
\text { to low altitude }\end{array}\end{array}$ & 133 & $6.12 \pm 1.58$ & $4.72 \pm 0.69$ & $139.26 \pm 20.11$ & $0.43 \pm 0.06$ & $128.20 \pm 32.29$ \\
$\begin{array}{c}\text { 30 d after return } \\
\text { to low altitude }\end{array}$ & 464 & $6.57 \pm 1.63^{(1)}$ & $5.41 \pm 0.58^{(1)}$ & $162.23 \pm 15.83^{(1)}$ & $0.50 \pm 0.05^{(1)}$ & $113.21 \pm 36.54^{(1)}$ \\
\hline
\end{tabular}

(1) $P<0.05$ compared with plain control group; ${ }^{(2)} P<0.05$ compared with $15 \mathrm{~d}$ after return to low altitude. 


\subsubsection{Changes in Hematological Indices among People Who Returned to Low Altitude after Living} in the Plateau for Five Years

The hematological indices among people who returned to the plain after working in the construction sites of Qingzang for more than five years were determined. It was found that their $\mathrm{Hb}$, Hct, and $\mathrm{MCH}$ were all higher compared with those of the plain controls, the Plt count was lower than that of the plain controls $(P<0.01)$, and the RBC count was similar to that of the plain controls (Table 14).

A correlation analysis demonstrated that when the body mass index (BMI), blood pressure, and age were restricted, Hb, Hct, MCH, and platelet large cell ratio (P-LCR) positively correlated with the altitude and duration of high altitude residence and negatively correlated with the duration of their return to low altitude. The Plt count was negatively correlated with the altitude and duration of high altitude residence and positively correlated with the duration of their return to low altitude (Table 15).

\subsubsection{Changes in the Hematological Indices among People Who Returned to Low Altitude after Living in the Plateau for a Long Time}

The RBC, Hb, and Hct counts of the subjects who returned to the plain after living in the plateau for a long time were similar to those of the plain controls $(P>0.05)$. To rule out the effects of the duration of their return to the plain on the hematological indices, the duration was divided into the following time periods: less than one year, 1 - 5 years, 5 - 10 years, 10 - 20 years, 20 - 30 years, and more than 30 years. The hematological indices at different periods were compared with those of the plain controls. The study showed that the Hb and Hct counts of those who returned to the plain for less than one year were higher than those of the plain controls $(P<0.05)$; over time, the differences disappeared. The results also demonstrated that the RBC and $\mathrm{Hb}$ counts of subjects who returned to the plain for more than 30 years were clearly lower than the plain controls. Because the RBC and Hb counts can be influenced by other factors, such as gender and age, the results were adjusted for gender and age. After this adjustment, the $\mathrm{Hb}$ level of subjects who returned to the plain for less than one year was still higher than the level of the plain controls, and the Hb level of other groups was similar to that of the plain controls (Table 16).

The Plt counts of subjects who returned to the plain after living in the plateau for a long time was similar to that of the plain controls; however, the Plt count of those who returned to the plain for less than one year, 1 - 5 years, 5 - 10 years, and 10 - 20 years was significantly lower than that of the plain controls. Moreover, after the adjustments for gender and age, the differences were still significant (Table 16). After the adjustment for gender and age, the Plt count of those who returned to the plain for more than 20 years was similar to that of the plain controls. The Plt count was positively related to the duration of the return to the plain $(r=0.137, P<0.05)$.

\subsubsection{Effects of Mountain Sickness on Hematological Indices of Plateau Migrants after They Return to Low Altitude}

The RBC count of those plateau migrants with mountain sickness was significantly higher those without mountain sickness. After the adjustment for gender and age, the differences in RBC count were also significant $(P<$ 0.05), while the differences in Hb and Hct were not significant (Table 17).

Table 14. Select hematological indices of plateau construction workers 45 months after they returned to low altitude areas $(\bar{x} \pm s)$.

\begin{tabular}{ccccccc}
\hline Group & Cases & RBC $\left(\times 10^{12} / \mathrm{L}\right)$ & Hb $(\mathrm{g} / \mathrm{L})$ & Hct $(\%)$ & MCH $(\mathrm{pg})$ & Plt $\left(\times 10^{9} / \mathrm{L}\right)$ \\
\hline Plain control group & 225 & $4.998 \pm 2.296$ & $145.58 \pm 15.23$ & $0.436 \pm 0.059$ & $30.11 \pm 3.95$ & $208.85 \pm 59.49$ \\
Observation group & 560 & $4.984 \pm 1.618$ & $156.02 \pm 15.56^{(1)}$ & $0.442 \pm 0.053^{(1)}$ & $31.68 \pm 3.51^{(1)}$ & $179.47 \pm 55.96^{(1)}$ \\
\hline
\end{tabular}

${ }^{(1)} \mathrm{P}<0.05$ compared with plain control group; MCH: Mean corpuscular hemoglobin.

Table 15. Partial correlation analysis of some hematological indices and plateau factors.

\begin{tabular}{|c|c|c|c|c|c|c|c|c|c|c|c|c|}
\hline \multirow{2}{*}{ Factors } & \multicolumn{2}{|c|}{ RBC } & \multicolumn{2}{|c|}{$\mathrm{Hb}$} & \multicolumn{2}{|c|}{ Hct } & \multicolumn{2}{|c|}{$\mathrm{MCH}$} & \multicolumn{2}{|c|}{ Plt } & \multicolumn{2}{|c|}{ P-LCR } \\
\hline & $r$ & $P$ & $r$ & $P$ & $r$ & $P$ & $r$ & $P$ & $r$ & $P$ & $r$ & $P$ \\
\hline Altitude of construction & 0.130 & 0.029 & 0.147 & 0.013 & 0.265 & 0.000 & 0.040 & 0.497 & -0.172 & 0.000 & 0.145 & 0.000 \\
\hline Time of altitude residence & 0.065 & 0.275 & 0.184 & 0.002 & 0.210 & 0.000 & 0.129 & 0.030 & -0.193 & 0.000 & 0.139 & 0.001 \\
\hline $\begin{array}{c}\text { Time of return to low } \\
\text { altitude }\end{array}$ & -0.099 & 0.096 & -0.187 & 0.002 & -0.259 & 0.000 & -0.106 & 0.075 & 0.194 & 0.000 & -0.193 & 0.000 \\
\hline
\end{tabular}

MCH: Mean corpuscular hemoglobin; P-LCR: Platelet large cell ratio; Control condition. Body mass index, blood pressure, age. 
Table 16. Select hematological indices of subjects who returned to low altitude after living in the plateau for a long time $(\bar{x} \pm s)$.

\begin{tabular}{ccccccc}
\hline Time of return to plain (year) & Cases (male) & Age (year) & RBC $\left(\times 10^{12} / \mathrm{L}\right)$ & Hb $(\mathrm{g} / \mathrm{L})$ & Hct $(\%)$ & Plt $\left(\times 10^{9} / \mathrm{L}\right)$ \\
\hline Plain control & $114(73)$ & $58.6 \pm 14.4$ & $4.75 \pm 0.52$ & $141.3 \pm 13.2$ & $42.04 \pm 5.28$ & $158.31 \pm 47.69$ \\
$<1$ & $15(10)$ & $45.7 \pm 6.3$ & $4.82 \pm 0.62$ & $149.1 \pm 19.4^{(1)}$ & $43.13 \pm 5.09$ & $129.53 \pm 36.41^{(1)}$ \\
$1-5$ & $69(29)$ & $53.9 \pm 9.9$ & $4.75 \pm 0.49$ & $142.7 \pm 14.6$ & $42.22 \pm 3.68$ & $136.84 \pm 59.43^{(1)}$ \\
$5-10$ & $84(46)$ & $60.4 \pm 7.5$ & $4.72 \pm 0.53$ & $141.4 \pm 15.6$ & $42.31 \pm 3.97$ & $137.04 \pm 52.87^{(2)}$ \\
$10-20$ & $92(51)$ & $63.2 \pm 10.7$ & $4.66 \pm 0.59$ & $138.2 \pm 14.3$ & $41.52 \pm 3.89$ & $139.22 \pm 57.80^{(2)}$ \\
$20-30$ & $53(27)$ & $65.6 \pm 10.4$ & $4.66 \pm 0.47$ & $139.7 \pm 13.1$ & $42.08 \pm 3.52$ & $149.83 \pm 45.70$ \\
$\geq 30$ & $49(16)$ & $69.6 \pm 10.3$ & $4.5 \pm 0.32$ & $135.7 \pm 10.8$ & $40.08 \pm 3.03$ & $180.73 \pm 55.01$ \\
\hline
\end{tabular}

Table 17. The effect of mountain sickness on the hematological indices of plateau migrants upon returned to low altitude $(\bar{x} \pm s)$.

\begin{tabular}{|c|c|c|c|c|c|}
\hline Group & Cases (male) & Age (years) & $\mathrm{RBC}\left(\times 10^{12} / \mathrm{L}\right)$ & $\mathrm{Hb}(\mathrm{g} / \mathrm{L})$ & Hct (\%) \\
\hline Plain control & $114(73)$ & $58.60 \pm 14.40$ & $4.75 \pm 0.52$ & $141.30 \pm 13.20$ & $42.04 \pm 5.28$ \\
\hline Observation group A & $83(41)$ & $62.54 \pm 11.54$ & $4.82 \pm 0.64^{(1)}$ & $141.42 \pm 17.93$ & $42.43 \pm 4.66$ \\
\hline Observation group B & 279 (138) & $60.99 \pm 11.09$ & $4.64 \pm 0.46^{(2)}$ & $139.60 \pm 13.35$ & $41.69 \pm 3.47$ \\
\hline
\end{tabular}

Observation group A. With mountain sickness history; Observation group B. Without mountain sickness history; ${ }^{(1)} P<0.05$ compared to the plain control group; ${ }^{(2)} \mathrm{P}<0.05$ compared to observation group A.

\section{Discussion}

Savourey [11] [12] and Grover [13] compared physiological indices of climbers before they ascended the mountain, while they were climbing the mountain, and after they returned to the plain. These studies found that the erythropoietin (EPO), adenosine triphosphate (ATP) concentration, partial pressures of oxygen, red blood cell count and volume, and other indices changed dramatically after the study subjects arrived at the mountain top. The indices restored to normal one to two months after the climbers returned to the plain. Risso and others [14] assumed that when mountain climbers returned to the plain from the plateau, abnormal environmental stimulants disappeared and brought no harm to the human body. However, most scholars reported that when high altitude natives (43 - 50 years old) traveled to sea level, their stroke index (SI) increased, their heart rate decreased, and the cardiac index (CI) remained unchanged [15] [16]. Du and others [17] investigated 590 cases of high altitude de-acclimatization syndrome in Golmud and found that $38 \%$ of the subjects presented with chest tightness, dizziness, sleepiness, weakness, anorexia, abdominal distension, and other clinical manifestations when they returned to the plain. The symptoms were related to age, the duration of high altitude residence, and labor intensity in the plateau. Older age and a longer duration of residence at high altitude both correlated with the development of high altitude de-acclimatization syndrome. Physical laborers were more likely to develop the disease than were mental workers. Cui and others [18] investigated 626 cases of high altitude de-acclimatization syndrome and found that the early symptoms were nervous and digestive, followed by respiratory and circulatory. After approximately one year, most subjects could overcome de-acclimatization and adapt to the new living environment.

In our study, the incidence of high altitude de-acclimatization syndrome was very high (84.36\%), and several body systems were affected, such as the hematological, digestive, circulatory, respiratory and nervous systems, which were consistent with studies by Cui and others [19]. However, we found that it took approximately one year for the hematological indices to return to normal, and in some cases, this process took more than four years [20]. The ventricular function and structure recovered slowly among plateau migrants after they returned to the plain. In subjects who lived on the plateau for a short time, the ventricular function and structure recovered one month after they returned to the plain, and the left ventricle recovered faster than the right ventricle. In subjects who lived in the plateau for more than five years, the ventricular function and structure recovered two to three years after the returned to the plain. In a few cases, the recovery time was more than four years. In subjects who lived on the plateau for more than ten years, the ventricular function and structure recovered five to ten years af- 
ter the return to the plain [20]. The results suggested the plateau migrants experienced high altitude de-acclimatization for a long time after they returned to the plain. These migrants may develop high altitude de-acclimatization syndrome if they do not overcome de-acclimatization, thus affecting their daily life and work and forcing a few to return to high altitude areas. Therefore, it is of great practical and clinical significance to improve the prophylaxis, diagnosis, and early treatment of high altitude de-acclimatization syndrome.

Because the diagnosis of high altitude de-acclimatization syndrome has not been standardized, it is vital to formulate diagnostic criteria. Our study demonstrated that high altitude de-acclimatization syndrome is different from other high altitude diseases. The latter often has typical symptoms and signs while the former does not have specific symptoms; instead, it has a series of non-specific symptoms such as dizziness, fatigue, weakness, sleepiness, diarrhea, cough, palpitation, chest tightness, vertigo, hair loss, increased appetite, and weight gain [21]. Physical examination shows no specific signs but may demonstrate some abnormal changes. First, the RBC, Hb, and Hct are higher than those of plain natives, and the Plt count is lower than that of plain natives [19]. Second, the plateau migrants experience cardiac abnormities, such as abnormal ventricular diastole, increased pulmonary arterial pressure, ventricular hypertrophy, and decreased left ventricular contraction. Right ventricular hypertrophy and increased RVOT and RVID/LVID are major changes experienced by this population [22][24]. Third, an examination of the urinary system may reveal proteinuria and increased microalbuminuria. Fourth, a chest X-ray examination could show an increased cardiothoracic ratio. Fifth, these patients may have low blood and pulse pressure [20]. Other tests, such as liver and kidney function, ECG, serum enzyme, and humoral immune function, cannot detect specific changes. Therefore, the diagnosis of high altitude de-acclimatization syndrome should be based on clinical symptoms, signs, and other examination results such as heart, lung, and hematological examinations.

In summary, although high altitude de-acclimatization syndrome does not have typical symptoms and signs, it manifests some specific changes in clinical symptoms, signs, and laboratory examinations. The changes are of high value in the diagnosis of high altitude de-acclimatization syndrome. Based on our epidemiological survey and multi-center randomized controlled clinical trial of more than 3000 subjects who returned to the plain from the plateau and the relevant literature, we have formulated diagnostic criteria for high altitude de-acclimatization syndrome.

\subsection{Necessary and Assistant Conditions of the Diagnosis}

The necessary conditions for the diagnosis [25]-[27] are recent return to the plain and more than three of the following symptoms, i.e., dizziness, fatigue, weakness, sleepiness, insomnia, palpitation, chest tightness, decreased appetite, general malaise, and memory loss, or presentation with dizziness, weakness, sleepiness, or general malaise. In addition, heart, lung, brain, kidney, and other organ diseases must be excluded, and the patient must not experience obvious alleviation of the above symptoms after short-term rest or symptomatic treatment.

The following conditions can assist in the diagnosis of de-acclimatization syndrome [28]-[30]: higher RBC, $\mathrm{Hb}$, and Hct than the maximum of the controls at the same altitude; Plt lower than the minimum of the controls at the same altitude; Serum myocardial enzyme creatine kinase-MB (CK-MB) and lactate dehydrogenase (LDH) activity lower than or equal to the mean of the controls at the same altitude; microalbuminuria; abnormal cardiac function; slightly higher pulmonary arterial pressure than the mean of the controls at the same altitude; weakened left and right ventricles (Tei indices increase and LVEF, RVEF, LVFS and RVFS decrease); right ventricular hypertrophy; increased RVOT and RVID/LVID; short-term memory loss; and higher total bilirubin, alanine transaminase (ALT), and aspartate transaminase (AST) levels than the mean of the controls at the same altitude; Serum testosterone and estradiol levels are lower, especially the estradiol level significantly lower than control group; bone mineral density testing. The ulna, radias and femoral or tibial fibular mineral density decreased significantly.

One can be diagnosed with high altitude de-acclimatization syndrome if one meets all of the necessary conditions and one of the assistant conditions.

\subsection{Evaluation Criteria of High Altitude De-Acclimatization Syndrome}

To accurately evaluate the severity of high altitude de-acclimatization syndrome, it is necessary to grade its symptoms and signs, which can assist in the objective evaluation of the symptoms. Thus, based on the studies by Cui and others [31], as well as our study, we have established the following grading and evaluation criteria (Table 18 and Table 19). 
Table 18. Grading and scoring criteria for the symptoms of high altitude de-acclimatization.

\begin{tabular}{ccc}
\hline Symptom classification & Evaluation standard & Score \\
\hline \pm & Mild symptoms, daily work affected, greatly improved after medication & $\mathrm{z}$ \\
+ & Severe symptoms, daily life affected, some alleviation after medication & 1 \\
++ & Severe symptoms, daily life affected, no significant relief after medication & 2 \\
++ & & 3 \\
\hline
\end{tabular}

Table 19. Grading diagnosis of high altitude de-acclimatization.

\begin{tabular}{cc}
\hline Classification & \multicolumn{1}{c}{ Diagnostic criteria } \\
\hline Almost no reaction $( \pm)$ & Suspicious symptoms $( \pm)$ or total scores 0 - 5 \\
Mild reaction $(+)$ & Slight symptoms $(+)$ or total scores $6-15$ \\
Moderate reaction $(++)$ & More serious symptoms $(++)$ or total scores $16-25$ \\
Severe reaction $(+++)$ & Very serious symptoms $(+++)$ or total scores $\geq 26$ \\
\hline
\end{tabular}

\subsection{Precautions in Scored Diagnosis of High Altitude De-Acclimatization Syndrome}

One can be diagnosed with high altitude de-acclimatization syndrome after the following diseases are ruled out: primary organ diseases such as heart, kidney, brain or lung diseases; malignant tumors such as leukemia and regenerative anemia; high altitude heart disease and erythema; and flu, upper respiratory tract infection, infectious diarrhea, and primary heart disease that are diagnosed after one returns to the plain.

In addition, subjects who live in different altitudes or perform different jobs in the plateau have different high altitude de-acclimatization syndrome frequencies after they return to the plain because the incidence of symptoms is positively correlated to the altitude of the plateau, the length of high altitude residence, and the labor intensity while on the plateau. Therefore, the physician should inquire about these details to ensure an accurate diagnosis. High altitude de-acclimatization syndrome indicates a poor adaptation to the environment among plateau migrants who return to low altitude or the plain. It is a non-specific syndrome with complex manifestations. It is not difficult to diagnose; however, one must consult diagnostic criteria and consider all of the clinical symptoms and signs to make an accurate diagnosis.

\section{Acknowledgements}

This randomized controlled study was supported by the infantry 56 brigade of PLA. Thanks are due to the 10th Hospital of PLA, the 4th Hospital of PLA, the 18th Hospital of PLA, Xianyang Center Hospital of China Railway First Group Corporation, and Hospital in Chengdu Office of the Tibetan Autonomous Region to give support in this project. This work was supported by the National Key Technology Research and Development Program of China (2009BAI85B03) and Health Subject of Chinese PLA (2013BJZ032).

\section{Authors' Contributions}

Zhou Q. Q., Yang S.Y., Yuan Z.C., Zhang X.F., and Wang G.S. designed the trial and analyzed the data. Zhou Q.Q. drafted the manuscript and obtained the funding. Zhang X.F., Shi Z.F., Yang Y.L., Wu Y.H., and Wang G.S. collected data. Wang Y.H., Zhang X.F., Shi Z.F., Yang Y.L., Wu Y.H., and Wang G.S. contributed to administrative, technical, and material support with project design guidance from a Zhou Q. Q. project. All authors had full access to all the data and take responsibility for the integrity of the data and the accuracy of the data analysis. All authors read and approved the final manuscript.

\section{Competing Interests}

All the authors certify that there is no actual or potential conflict of interest. In this study, Zhou Q.Q. is responsible for project design and data collection, paper writing, Yang S.Y., Yuan Z.C., Zhang X.F., Shi Z.F., Yang 
Y.L., Wu Y.H., Wang F.L., Wang G.S. and Zhou Q.Q., etc. are responsible for data acquisition and experimental observation respectively. Each division of labor is clear, everyone's responsibility is clear, and there is no conflict of interest among all the authors.

\section{References}

[1] Gao, Y.Q. (2005) High Altitude Military Medicine. Chongqing Publishing House, Chongqing, 237-238.

[2] Zhang, Y.B., Wang, Y., Liu, X.L., Feng, G.F. and Zhao, D.Y. (1996) Human and High Altitude. Qinghai People’s Publishing House, Xining, 97-319.

[3] Lv, Y.D. (1995) High Altitude Medicine and Physiology. Tianjing Scientific and Technical Translation Publisher, Tianjing, 605-607.

[4] Wu, T.Y., Li, W.S., Wang, X.Z., Miao, C.Y., Zhang, S.J., Zhang, X.H., Zhang, L.Z. and Song, C.P. (1992) Physiological and Clinical Study of De-Acclimatization among People Who Return to the Plain after Long-Term Residence in the Plateau. Journal of High Altitude Medicine, 2, 1-4.

[5] Wang, X.J., Zhu, H.J., Mao, H.Q. and Wang, Y.M. (1997) A Questionnaire Survey of People Who Return to the Plain after Long-Term Residence in the Plateau. Journal of High Altitude Medicine, 7, 25-27.

[6] Zhu, P., Li, G.X. and Gao, L.G. (1995) SCL-90 Test of De-Acclimatization among Cadres Who Return to the Plain After Long-Term Residence in the Plateau. Journal of High Altitude Medicine, 5, 16-18.

[7] Han, G.L. (2009) Effects of High Altitude Hypoxia on Human Cognitive Functions. Journal of High Altitude Medicine, 19, 15-18.

[8] Hu, J.F. (1992) Memory "De-Acclimatization” among High Altitude Natives Who Come to the Plain. Journal of Qinghai Medical College, 13, 82-85.

[9] Shi, Z.F., Zhou, Q.Q., Ma, S.D., Yan, C.J. and Xiang, L. (2011) A Survey of High Altitude De-Acclimatization Syndrome among Officers and Soldiers Who Returned to the Plain from Earth-Stricken Area. Journal of Preventive Medicine of Chinese People's Liberation Army, 29, 114-115.

[10] Fan, Y., Liu, X.L., Li, X.C., Yang, C.D., Wang, L. and Zhou, Q.Q. (2012) Investigation on the De-Adaptation Response about the Plateau Duty Forces Returned to the Plains. Modern Preventive Medicine, 39, 1863-1870.

[11] Savourey, G., Garcia, N., Besnard, Y., Guinet, A., Hanniquet, A.M. and Bittel, J. (1996) Pre-Adaptation, Adaptation and De-Adaptation to High Altitude in Humans: Cardio-Ventilatory and Haematological Changes. European Journal of Applied Physiology and Occupational Physiology, 73, 529-535. http://dx.doi.org/10.1007/BF00357675

[12] Savourey, G., Garcia, N., Caravel, J.P., Gharib, C., Pouzeratte, N., Martin, S. and Bittel, J. (1998) Pre-Adaptation, Adaptation and De-Adaptation to High Altitude in Humans: Hormonal and Biochemical Changes at Sea Level. European Journal of Applied Physiology and Occupational Physiology, 77, 37-43. http://dx.doi.org/10.1007/s004210050297

[13] Grover, R.F., Weil, J.V. and Reeves, J.T. (1986) Cardiovascular Adaptation to Exercise at High Altitude. Exercise \& Sport Sciences Reviews, 14, 269-302. http://dx.doi.org/10.1249/00003677-198600140-00012

[14] Risso, A., Turello, M., Biffoni, F. and Antonutto, G. (2007) Red Blood Cell Senescence and Neocytolysis in Humans after High Altitude Acclimatization. Blood Cells, Molecules, and Diseases, 38, 83-92. http://dx.doi.org/10.1016/j.bcmd.2006.10.161

[15] Vogel, J.A., Hartley, L.H. and Cruz, J.C. (1974) Cardiac Output during Exercise in Altitude Natives at Sea Level and High Altitude. Journal of Applied Physiology, 36, 173-176.

[16] McKenzie, D.C., Goodman, L.S., Nath, C., Davidson, B., Matheson, G.O., Parkhouse, W.S., Hochachka, P.W., Allen, P.S., Stanley, C. and Ammann, W. (1991) Cardiovascular Adaptations in Andean Natives after 6 wk of Exposure to Sea Level. Journal of Applied Physiology, 70, 2650-2655.

[17] Du, Z.M., Yu, Z.J., Liu, C.L. and Liu, K.L. (1993) A Survey of High Altitude De-Acclimatization Syndrome among 590 People in Golmud. Journal of Preventive Medicine of Chinese People’s Liberation Army, 11, 374-376.

[18] Cui, S.Z., Tang, S.Y., Niu, W.Z. and Wu, Y.A. (1999) A Survey of High Altitude De-Acclimatization Syndrome among 626 Plateau Migrants after Their Return to the Plain-Duration of the Symptoms. Medical Journal of National Defending Forces in Southwest China, 9, 47-49.

[19] Yuan, Z.C. (2009) Hematological Changes of Plateau Migrants after Their Return to the Plain. Journal of Environment and Health, 26, 522-524.

[20] Yuan, Z.C., Wang, X.L., Hou, M.Y., Lian, D. and Zhou, Q.Q. (2010) Blood Pressure, ECG and Cardiothoracic Ratio of Plateau Migrants after Their Return to the Plain. Journal of Environment and Health, 27, 987-990.

[21] Li, M.X., Wu, Y.H., Yin, W.Q., Tang, S.X., Zhou, Y. and Zhou, Q.Q. (2013) Changes of the Width of Right Inferior 
Pulmonary Artery and Cardiothoraoc Ratio in Han People Returning to Plain at Least 3 Years after Long-Term Exposure to High Altitude. Sichuan Medical Journal, 34, 1288-1291.

[22] Yang, S.Y., Feng, E.Z., Yan, Z.Q., Huo, W. and Tian, Z.X. (2010) Relationship between Acute High Altitude Reaction and Pulmonary Arterial Pressure in High Altitude Combined with Heavy Physical Work and Body Changes after Return to Lower Altitude. Chinese Journal of Lung Diseases (Electronic Edition), 3, 90-94.

[23] Wu, Y.H., Xiao, R., Tang, S.X., Sun, Z.M., Yin, W.J., Li, X.P., Sun, Y.C. and Zhou, Q.Q. (2013) Changes of the Cardiac Structure and Function in Han People Returning to the Plain for at Least 3 Years after Long-Term Exposure to High Altitude. Modern Preventive Medicine, 40, 3162-3164.

[24] Feng, E.Z., Yang, S.Y., Yan, Z.Q., He, W., Tian, Z.X., Yin, H., Ma, L.F., Shi, Z.F. and Zhou, Q.Q. (2012) De-Acclimatization Change in Cardiac Function of Laborers Engaged in Physical Labor at High Altitude after Returning to Lower Altitude. Medical Journal of Chinese People's Liberation Army, 37, 905-909.

[25] Zhou, Q.Q., Yang, S.Y., Luo, Y.J., Qi, Y.S., Yan, Z.Q., Shi, Z.F. and Fan, Y. (2012) A Randomly-Controlled Study on the Cardiac Function at the Early Stage of Return to the Plains after Short-Term Exposure to High Altitude. PLoS ONE, 7, e31097.

[26] He, B.f., Wang, J.C., Qian, G.S., Hu, M.D., Qu, X.M., Wei, Z.H., Li, J., Chen, Y., Chen, H.P., Zhou, Q.Q. and Wang, G.S. (2013) Analysis of High-Altitude De-Acclimatization Syndrome after Exposure to High Altitudes: A Cluster-Randomized Controlled Trial. PLoS ONE, 8, e62072.

[27] Yang, S.Y., Zhou, Q.O., Fen, E.Z., Yan, Z.Q., Tian, Z.X., Yin, H., Shi, Z.F. and Fan, F. (2013) Relationship between Acute High Altitude Response, Cardiac Function Injury, and High Altitude De-Acclimatization Response after Returning to Lower Altitude. Occupational Diseases and Environmental Medicine, 1, 4-10. http://dx.doi.org/10.4236/odem.2013.11002

[28] Shi, Z.F., Zhou, Q.Q., Xiang, L., Man, S.D., Yan, C.J. and Luo, H. (2011) Three Preparations of Compound Chinese Herbal Medicines for De-Adaptation to High Altitude: A Randomized, Placebo-Controlled Trial. Journal of Chinese Integrative Medicine, 9, 395-401. http://dx.doi.org/10.3736/jcim20110408

[29] Yang, Y.L., Zhou, Q.Q., Yang, L. and Zhang, Y. (2012) Hematological Changes in Officers and Soldiers Returning to Plain from High Altitude after Earthquake Relief Work. Medical Journal of National Defending Forces in Northwest China, 33, 117-119.

[30] Yang, Y.L., Zhou, Q.Q. and Shi, Z.F. (2012) Changes of Some Biochemical Indexes in De-Adaptation of People back to Low Altitude after a Short-Term Exposure to High Altitude. Medical Journal of National Defending Forces in Northwest China, 14, 803-806.

[31] Cui, S.Z., Tang, S.Y., Niu, W.Z. and Wu, Y.A. (1998) A Survey of High altitude De-Acclimatization Syndrome among 626 Plateau Migrants after Their Return to the Plain-Grading Criteria. Medical Journal of National Defending Forces in Northwest China, 8, 176-177. 


\section{Abbreviation}

ECG: Electrocardiogram;

SMS: Severe mountain sickness;

MAMS: Mild mountain sickness;

NAMS: No mountain sickness;

PC: Plain control;

RVID/LVID: Right ventricular internal diameter/left ventricular internal dimension;

Tei index: Myocardial performance index;

LVEF: Left ventricular ejection fraction;

LVFS: left ventricular tractional shortening;

mPAP: Mean pulmonary arterial pressure;

RVID: Right ventricular internal diameter;

RVOT: Right ventricular outflow tract;

LVID: Left ventricular internal dimension;

WBC: White blood cell;

RBC: Red blood cell;

Hb: Hemoglobin;

Hct: Hematocrit;

MCV: Mean corpuscular volume;

MCH: Mean corpuscular hemoglobin;

Platelet: Plt;

BMI: Body mass index;

SI: Stroke index;

CI: Cardiac index;

P-LCR: Platelet large cell ratio;

EPO: Erythropoietin;

ATP: Adenosine triphosphate;

CK-MB: Creatine kinase-MB;

LDH: Lactate dehydrogenase;

ALT: Alanine transaminase;

AST: Aspartate transaminase. 
Scientific Research Publishing (SCIRP) is one of the largest Open Access journal publishers. It is currently publishing more than 200 open access, online, peer-reviewed journals covering a wide range of academic disciplines. SCIRP serves the worldwide academic communities and contributes to the progress and application of science with its publication.

Other selected journals from SCIRP are listed as below. Submit your manuscript to us via either submit@scirp.org or Online Submission Portal.
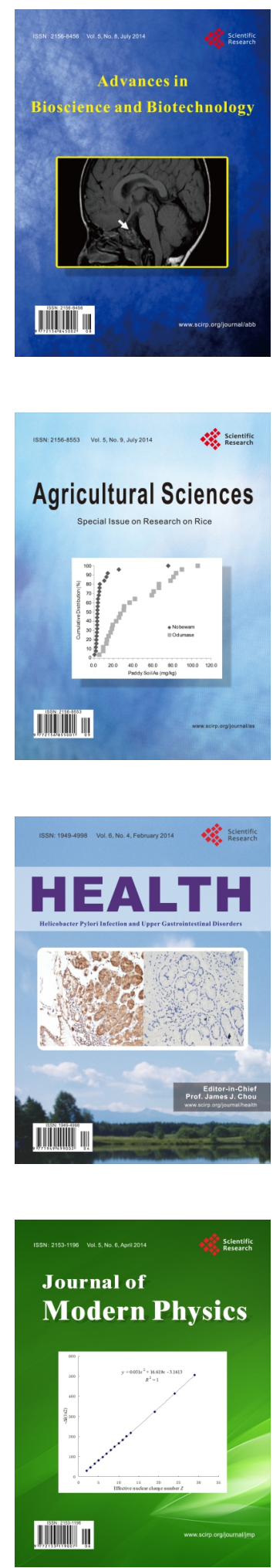
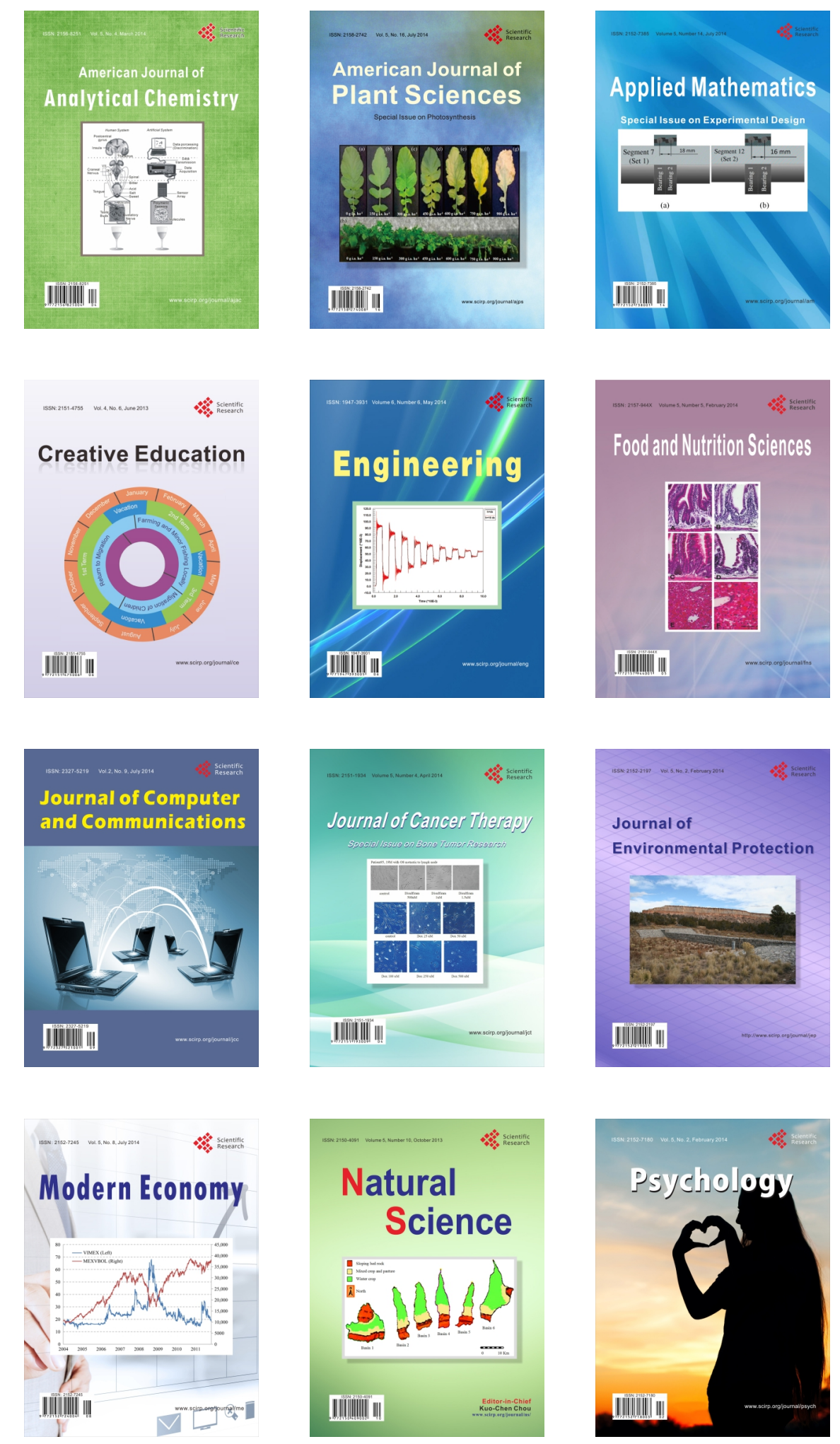